\title{
Description Profile of Understanding Layer Concept of Conic Section of Mathematics Education Students 2016 of FKIP UKSW
}

\author{
$1^{\text {st }}$ Fithri Anna Fauziyyah \\ ${ }^{1}$ Student of Mathematics Education FKIP \\ UKSW \\ Salatiga Indonesia \\ 202013072@student.uksw.edu
}

\author{
$2^{\text {nd }}$ Kriswandani \\ Lecturer of Mathematics Education FKIP \\ UKSW, \\ Salatiga Indonesia \\ kriswandani@staff.uksw.edu
}

\begin{abstract}
This qualitative descriptive study aimed to describe the profile of understanding layer of the Conic Section concept toward Mathematics Education Students 2016 of FKIP UKSW. The understanding layer includes eight layers, Primitive Knowing (Pk), Image Making (Im), Image Having (Ih), Property Noticing (Pn), Formalising (F), Observing (O), Structuring (S), and Inventising (Iv). Subjects were taken by purposive sampling technique and obtained 5 Mathematics Education Students 2016 of FKIP UKSW. Data collection techniques include observation, testing, and interview. Data analysis techniques are data reduction, data presentation, and conclusion. Based on the findings, there are some points exposed:1) to solve problem about determining a point on the circle, all subjects using Iv layers; 2) to solve the problem of parabolic equation, $60 \%$ of the subjects using Iv layer, and respectively $20 \%$ of the subjects using Im and Ih layers; 3) to solve problem of parabol focal point, $60 \%$ of the subjects using Im layer, and respectively $20 \%$ of the subjects using Iv and Ih layers; 4) to solve problems in the area of Ellipse, $60 \%$ of the subjects using Im layer, and respectively $20 \%$ of the subjects using Iv and Pn layers; 5) to solve problem of the distance to the center point of the peak, $40 \%$ of the subjects using Iv layer, and respectively $20 \%$ of the subjects using $\mathrm{O}, \mathrm{Pk}$, and $\mathrm{F}$ layers; 6 ) to solve problem of the hyperbolic equation, $20 \%$ of the subjects using Pn layer, and respectively $40 \%$ of the subjects using Iv and Ih layers; and 7) to solve problem on the hyperbolic asymptote, $60 \%$ of the subjects using Im layer, and respectively $20 \%$ of the subjects using Iv and Ih layers.
\end{abstract}

Keywords-Understanding Layer Concept, Conic Section, Mathematics Education Student

\section{INTRODUCTION}

Mathematics is one of the disciplines in the world of education plays an essential role in the development of science and technology and the development of other knowledge, such as in social, law, medical, sociology, chemistry, physics, geography, and so on. Mathematics has a significant role in life in which mathematics can develop and train the logical thinking pattern, analytical, systematic, critical, and creative as well as the ability to cooperate in dealing with various problems and be able to utilize the information received [1]. Mathematics consists of a variety of concepts in which one and another concept are interrelated. Therefore, to study mathematics needs the ability to understand mathematical concepts. This discourse is based on the Ministerial Regulation No. 59 of Curriculum 2013, which states that understand the mathematical concept related to the ability to explain the link between the concept and the use of concepts and algorithms in a flexible, accurate, efficient, and precise in problem-solving [2].

The understanding of the concept consists of two words, i.e., understanding and concepts. Understanding refers more to how students are able to understand well what is proved and able to provide explanations. If a person understands something, that person understands well and is able to explain the things he understands. Understanding as making connections between ideas, facts, or procedures in which the level of understanding is directly related to the characteristics of the connection. Understanding the concept is the ability to capture notions like being able to understand what is being taught, giving a more detailed explanation in own sentence, restating the concept, classifying an object and discloses a material that is presented in a form that is more easily understood (to use his own sentence) [3]\&[4].

In mathematics, there is a mathematical term. Understanding of mathematics as knowledge of the mathematical idea that is based on the facts of the statement of the ideas of the knowledge structured according to the procedures and can be obtained on the basis of prior knowledge in the formation of mathematical ideas, the changes will take place from knowledge to the formation of mathematical ideas specifically [4]. Understanding of mathematics is one of the skills or proficiency mathematical expected to be achieved in learning mathematics by demonstrating mathematical comprehension learned, explaining the link between concepts and applying concepts or algorithms flexibly, accurately, efficiently, and being precise in problem-solving. The basis of understanding mathematics that most dramatically affects is the first ability or previous ability. The more improved student's understanding of early mathematics, the next understanding of mathematics, then will be good too, to produce quality and level of proper understanding of mathematics, as well as to produce the quality of mathematics education with a high level of mathematical understanding.

Understanding is composed of eight levels (layers), the Primitive Knowing (Pk), Image Making (Im), Image Having (Ih), Property Noticing (Pn), Formalising (F), Observing (O), 
Structuring (S), and Inventising (Iv) [4]\&[5]. This theory states that understanding is not always linear and continuous growth. Someone often returns to the layer of previous understandings to the further advance of the next level of understanding. This layer can be illustrate in the following picture (Fig.1.).

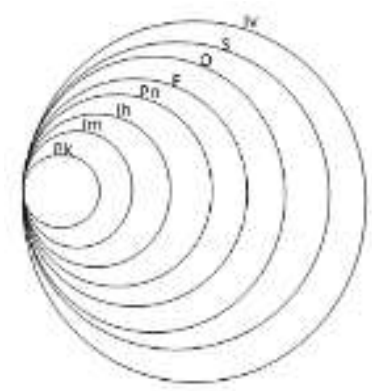

Fig. 1. Pirie \& Kieren Development of Understanding Mathematics Level

The indicator layer upon layer of that understanding. The first layer of primitive knowing is the first effort made by students in understanding the most basic definition to build next understanding through action which involves the definition or represents definitions. The second layer of understanding, image making is a stage where students create an understanding of previous knowledge and use it as their initial knowledge of materials studied to produce new knowledge in that material. The third layer of understanding image having is a stage where students already have an idea of the subject-matter of the material being studied and create an abstract picture on the subject without having to work on examples. The fourth layer regard to the property noticing is a stage where students are able to combine the concepts of a topic to establish specific properties on that topic. The fifth layer of understanding formalizing is a stage in which students create abstractions and connect a mathematical concept based on the properties that appear, forming a definition of the concept of the material. In this case, the student is able to associate such materials with mathematical concepts contained in those materials. The sixth layer of understanding is observing, on this layer, students are able to observe using the concepts that have been connected to the material so that students are able to associate their understanding of mathematical concepts with new knowledge structures. The seventh layer of understanding is structuring, on this layer of students have been able to construct their understanding as well as a link between a theorem from one another and be able to prove it with logical arguments. Students are also able to prove the connection between one theorem to another axiomatically. The eighth layer of understanding is inventisiing, on the last layer the student has found a complete structured understanding that they do not know before and students are able to create new questions of the problem or the material they are learning [47].

Conic Section is the material that existed in the 1994 curriculum, then dispensed and existed again in 2013. This curriculum is supported by National Education Minister Regulation No. 21 of 2016 on the Content Standards for Primary and Secondary Education which states that one of the competencies that will be examined, i.e., understand the similarities of various conic sections, graphics, and its relation [2]. This conic section material is considered difficult by students and teachers. Based on the results of Field Experience Practice shows that 53\% of students did not complete the Daily Exam of Conic Section. Some teachers argue that it needs time to learn more conic section to convey well to the students. Based on complaints from teachers, it is needed to understand more about Conic Section material as a prospective student Teacher of Mathematics. One example of a layer of understanding the concept of Mathematics Students in 2016 in solving the problems conic sections.

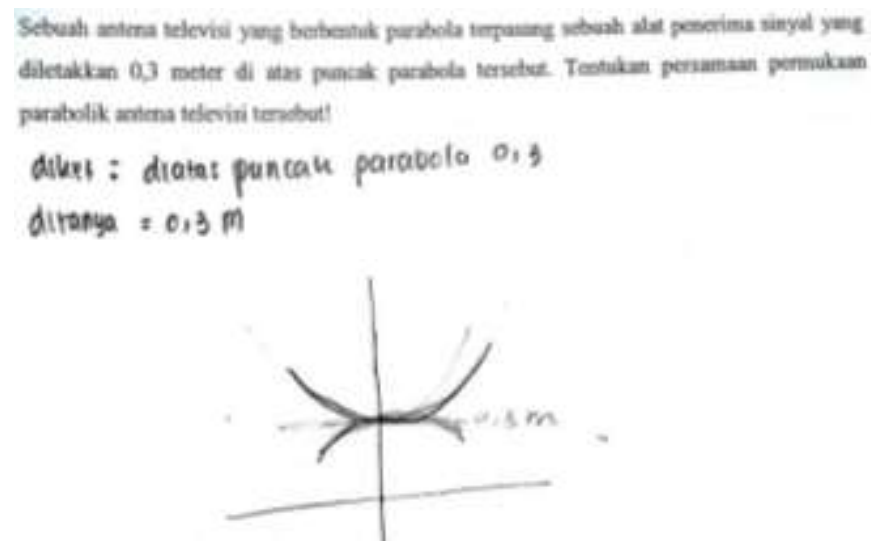

Fig. 2. Results of Test No. 2 Subject 2

Based on the results of tests and interviews, Subject 2 lacks the simple knowledge of the issues presented. Subject 2 only understands if there is a parabola with a signal receiver are placed 0.3 meters above the top of the parabola. Subject 2 does not even know where the parabola was facing and where the location of the signal receiver which is a focal point. Subject 2 also does not know how the general parabolic equation. When Subject 2 asked to describe the parabolic, Subject 2 only drew randomly without knowing for sure about the parabola. It shows that the subject is only reached in understanding layers of Image making (Fig.2.).

Based on the background and research problems above can be formulated purpose of this study was to describe the profile conceptual understanding layer Conic Section of Mathematics student 2016 of FKIP UKSW.

\section{METHODS}

The research is a qualitative descriptive study. The subjects in this study were determined by using retrieval techniques in the form of purposive sampling so elected five students of Mathematics batch 2016. They have studied about conic section in basic mathematics in semester 1 . We choose them The instrument used consisted of the main instruments and supporting instruments. The primary instrument is the researchers themselves, while the supporting instrument is essay test consists 7 question about conic section and guidelines for the interview. Data collection techniques in this study are the observation, testing, and in-depth 
interviews. Data analysis techniques in this research are data reduction, data presentation, and conclusion.

\section{RESULTS AND DISCUSSION}

Problem is given to the subject matter of the material is seven questions about Conic Section. The following is a discussion of the work subject.

\section{A. Analysis of Problem Number 1}

The questions provided are:

Andy was playing marbles with his friends. In a circle that has the equation $x^{2}+y^{2}-6 x-4 y-3=0$, there are two marbles more. When Andi was throwing the marbles, the marbles contained in each circle bouncing with position (7,

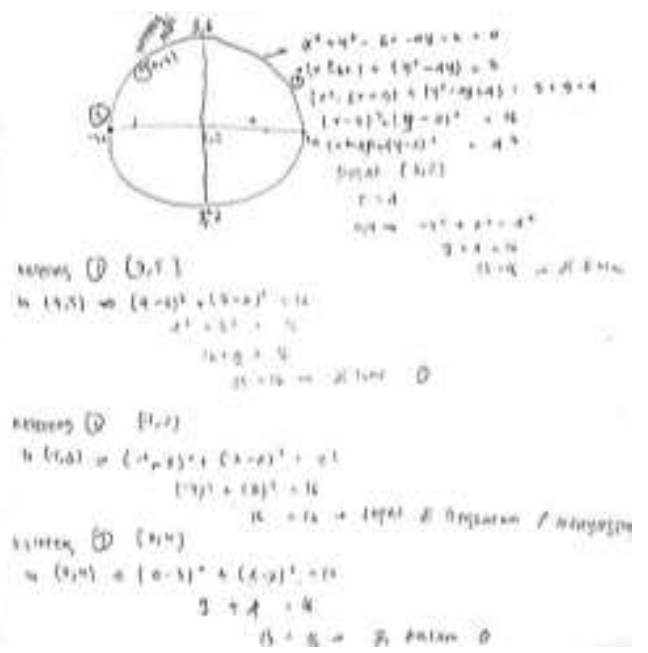

(i)

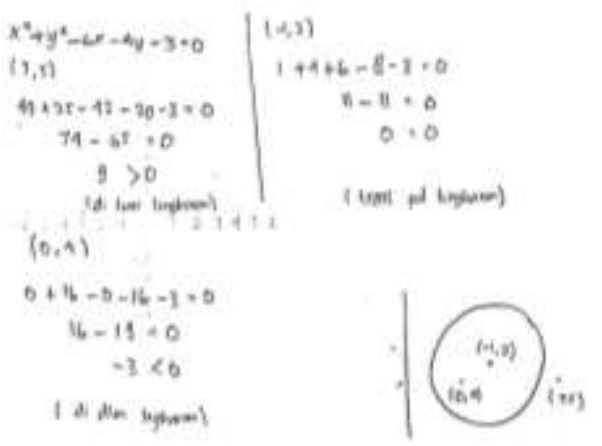

(iii)
5) and $(-1,2)$. Meanwhile, Andi's marbles are in position (0, $4)$. Where are the positions of each marble on that circle?

Problem number one is a question concerning the position of a point on the circle. Subjects can solve the problem by substituting point known to the equation of the circle and then compare the results with the right side (in this case is 0 ). Subjects were then able to conclude if the result is less than zero then the point is inside the circle, if the result is zero then the point is right on the circle, whereas if the result is greater than zero then the point is outside the circle. Here are answers from each subject in solving problems concerning the position of the point of the circle.

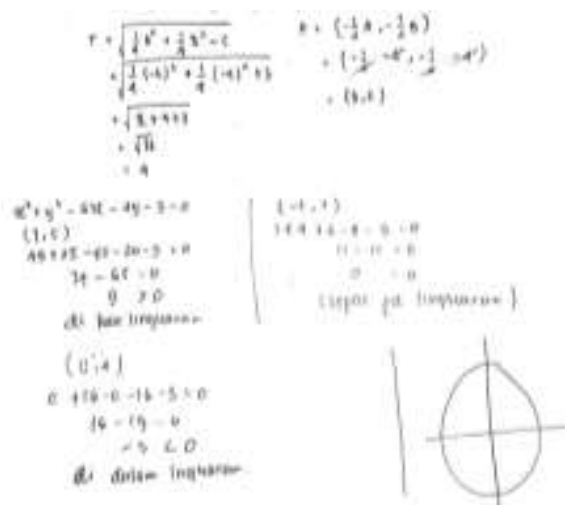

(ii)
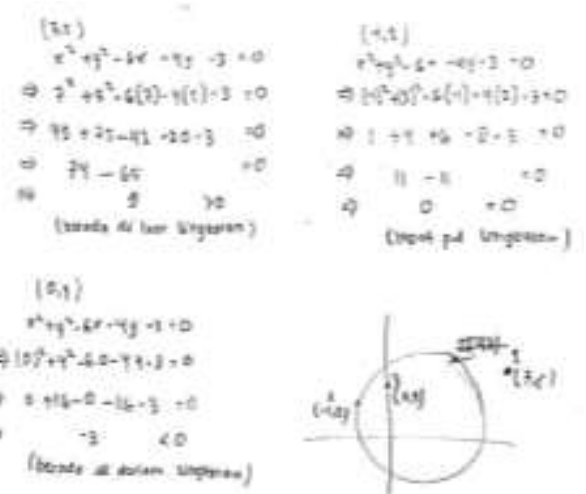

(iv) 


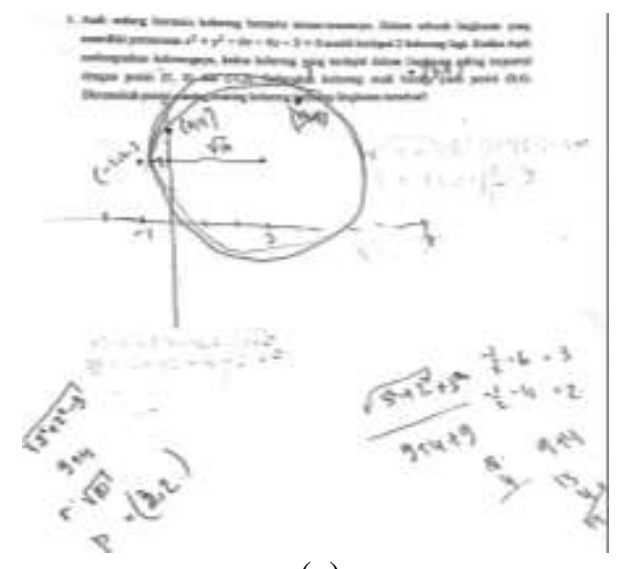

(v)

Fig. 3. The answer of each subject about problem Position Point of the Circle

Based on their answer and the interview result, they can solve the problem about the position of a point on the circle to the inventising layer. See Fig. 3(i); Subject 1 can describe a circle then substitutes each coordinate into the equation of the circle to the conclusion that the position point of a circle. Subject 1 then completes the circle that has been drawn with several points. See Fig. 3(ii), Subject 2 substitutes each coordinate into the circle equation to get the conclusion that the position point of the circle, but Subject 2 only describes a circle without its point. See Fig. 3(iii); Subject 3 substitutes each coordinate into the equation circle to get the conclusion that the position point of a circle. However, subject 3 is less able to distinguish the position point located in and on the circle so equally placed. This discourse indicates that the subject 3 sufficiently creates the mathematical structure on the position point of the circle, although it is not adequately described. See Fig. 3(iv); Subject 4 is able to describe a circle then substitute each coordinate into the equation circle to the conclusion that the position point on the circle, then complete the circle that has been drawn on several points. See Fig. 3(v); Subject 5 can create a mathematical structure correctly; however subject 5 is less accurate in using radius circle formulas that is $\sqrt{\frac{1}{2} A^{2}+\frac{1}{2} B^{2}-C}$ supposed to

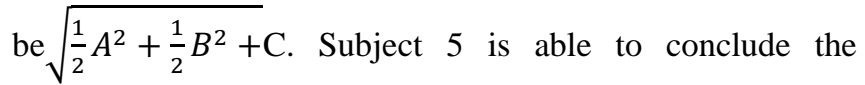
outcome, although by drawing it directly in Cartesian coordinates. Subject 5 also makes some mistake in counting several times. Based on their answer, we conclude that their understanding level on the inventising layer cause they can create a mathematical structure of position point on the circle, but several of them cannot complete explaining step by step correctly, and Subject 5 describe position point on the circle with his understanding.

\section{B. Analysis of Problem Number 2}

The questions provided are:

A parabolic television antenna installed a signal receiving device that is placed 0.3 meters above the top of the parabola. Find the equation parabolic surface of the television antenna! Problem number 2 is about parabolic equation problem. Subjects can finish by substituting $(0,0.3)$ as the focal point into the general equation of a parabola. Here are the answers to each of the subjects in solving the parabolic equation.

$$
y^{2}, A p x
$$

drues: deabs puncule paratolo ars

ditaseos $=0.3 \mathrm{~m}$
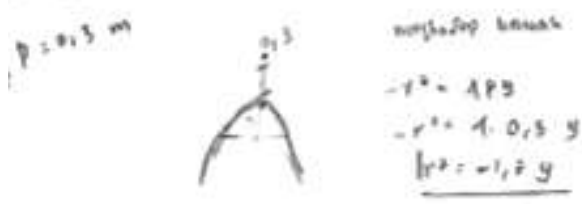

(i)

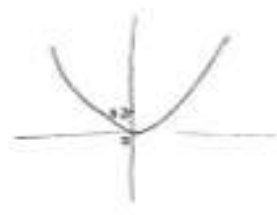

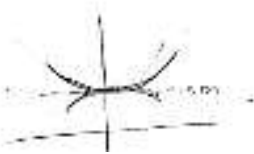

(ii)

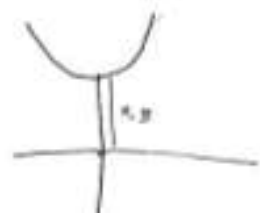

(iii)
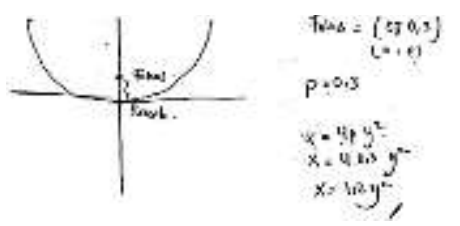

$x^{*}=1,2 y$ 
Fig. 4. The answer of each subject about Parabolic Equation Problem

Based on the test and interview results, the subject can solve the problem about the parabolic equations, but there are two subjects have an understanding level on the image making layer, and three subjects have an understanding level on the inventising layer. See Fig. 4(i), Subject 1 can draw and determine the parabola equation, but Subject 1 has less explicit assumptions that parabola facing down should be upwards. Subject 1 can create the mathematical structure of the parabolic equation, although it has less explicit assumptions regarding the parabola position. See Fig. 4(ii); Subject 2 can solve the problem about parabolic equation up to image making layer. Subject 2 is only able to draw a parabola randomly without knowing the parabola position. See Fig. 4(iii); Subject 3 can solve the parabolic equation until the image having a layer. Subject 3 is able to draw the

\section{Analysis of Problem Number 3}

The questions provided are:

There is a cross-section of a plate radio antenna in the form of a parabola. A technician has put a point on the crosssection of 0.75 -meter antennas on top and 6 meters on the right from its center point. At the which coordinates the technician should put the focus of the antenna?

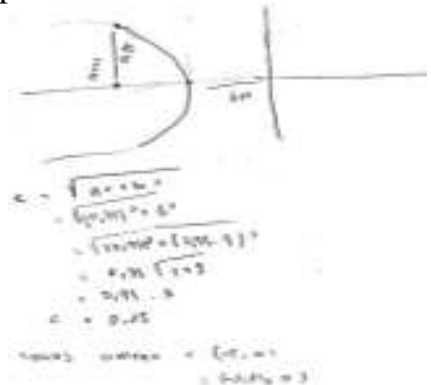

(i) parabola facing upwards, but less to have a description of the location of the focus point. Subject 3 already has an abstract image of parabolic equations, but less precise for the subject uses equation $y^{2}=4 p x$ that supposed to be $x^{2}=4 p y$. See Fig. 4(iv); Subject 4 can solve parabolic equation problem to the inventising layer. Subject 4 is able to draw the parabola to determine its equation. This discourse indicates that subject 4 can create a mathematical structure of parabolic equation. See Fig. 4(v); subject 5 can solve parabolic equation problem to inventising layer. Subject 5 can draw the parabola to determine the equation of a parabola, but less precise in using a parabolic equation $x=4 p y^{2}$ that supposed to be is $x^{2}=4 p y$. This indicates that subject 5 can create the mathematical structure of the parabolic equation.

Problem number 3 is a problem regarding the location of the focus point. Subjects can finish with substitute point $(6 ; 0.75)$ into the general equation parabola thus obtained $p$ which is the focal point. Here are answers to each subject in resolving the problem of the focal point of the parabola.

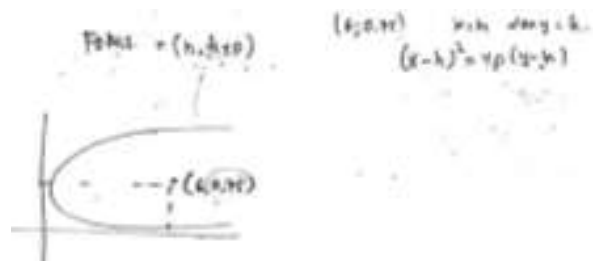

(iv)

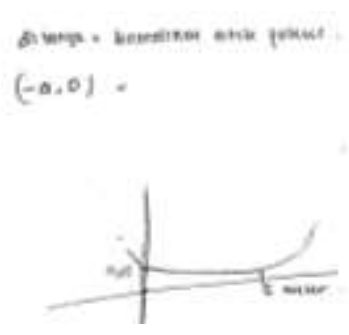

(ii)

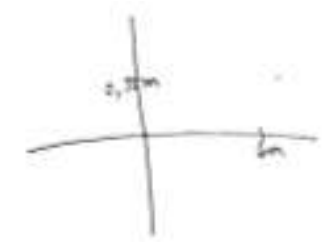

(iii)

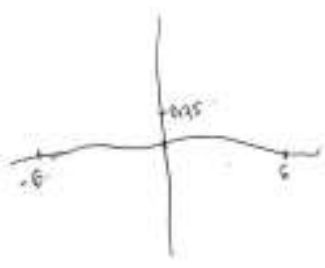

(v)

Fig. 5. The answer of each subject about Focusing Parabolic Problem

Based on answer the test and interview results, while determining the location of the focal point, there is only one subject who can solve this problem until inventising layer and another subject until image making layer. They understand the definition about focusing parabola, and they make parabola in Cartesian coordinate. See Fig. 5(i), subject 1 can solve problems about the location of the focal point to the inventising layer. Subject 1 lacks in creating the 
mathematical structure of the location of the focal point, but not precise in some things. Therefore, those things make subject 1 is not sure about the completion made. Subject 2 can solve the problem about the location of the focal point to image making layer. Subject 2 is good enough in drawing the parabola upright, but unable to determine the position of a point and mention the focal point of the parabola is $(-a, 0)$ that supposed to be $(0, p)$. The answer is presented in Fig. 5(ii). More confused than subjet 2 answer, subject 3 is only able to draw axes $x$ and $y$ coordinate with point 6 on the axis $x$ and 0.75 on the axis $y$ without being able to draw the parabola, and the answer in Fig. 5(iii). She understood the problem, and she can explain relation about the problem with parabola concepts, but she cannot draw correctly. Based on test results and interview subject 3 can solve problems regarding the location of the focal point to image making layer. See Fig. 5 (iv); subject 4 is able to solve problems number 3 until the image having the layer. Subject 4 had a pretty good plot in solving the problems, however subject 4 is less precise in assuming when the parabola peaked at $(h, k)$ while the parabola is meant to be peaked at $(0,0)$. Based on Fig. 5(v), similar to subject 3 answer, subject 5 can solve problems regarding the location of the focal point to image making the layer. Subject 5 can only draw the coordinate axes $x$ and $y$ with points 6 and -6 on the $x$-axis and 0.75 on the axis $y$ without being able to draw the parabola asked.

\section{Problem Analysis Number 4}

The questions provided are:

Point $\mathrm{P}$ on the ellipse $\frac{x^{2}}{a^{2}}+\frac{y^{2}}{b^{2}}=1$ with a focus $S_{l}$ and $S 2$.If $L$ is a triangular area $P S_{I} S_{2}$, what is the maximum value of L?

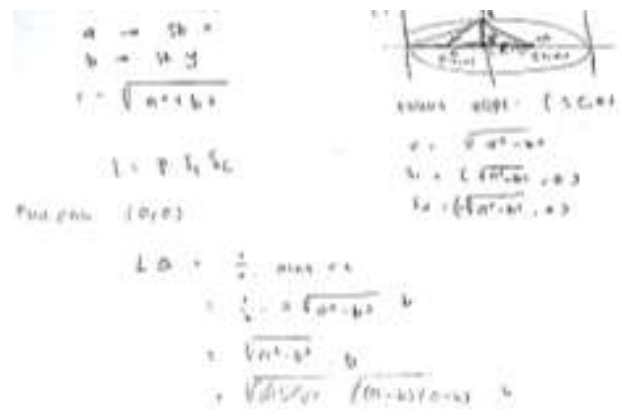

(i)

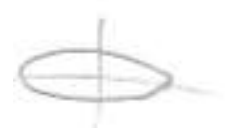

(iii)

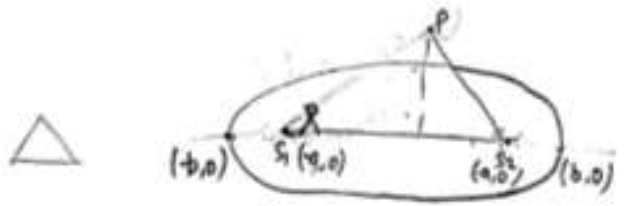

(iv)
Problem number 4 is the problem of the area inside the ellipse. Subjects are able to solve the problems by identifying the base and maximum height in the triangle which is the length of major and minor axes of the ellipse. Here are answers to each subject in solving problems of the area inside the ellipse.

Based on test results and interview, there is four subject which their understanding level of image making layer and only one subject have inventising layer. See Fig. 6(i); Subject 1 can solve problems regarding the area inside the ellipse to the inventising layer. Subject 1 can create a mathematical structure of prior knowledge well. Subject 1 can draw and determine the extent of the area asked, but less able to simplify the final result $L S_{1} S_{2}$ is $\sqrt{a^{2}+b^{2}} \cdot b$ that can be simplified to $C B$. See Fig. 6(ii), 6(iii), 6(iv), and 6(v) which show their subjects have understanding level on image making layer. They understood ellipse concepts, but they cannot determine the maximum value if L. Subject 2 only draw a triangular randomly, without knowing what steps should be taken later. Almost the same, Subject 3 can only draw ellipse and triangle too, without being able to determine the location of the focal point and $P$. Subject 4 can solve problems on the area of the triangle up to property noticing layer. Subject 4 is able to draw an ellipse but less precise to put the $a, b$, and $c$ point. Subject 4 knows the area of a triangle and shows each element, but does not know the length of each base and height. Subject 5 can solve problems in the area inside the ellipse to image making the layer. Subject 5 can only draw an ellipse without knowing where the position of the focal point and the $P$ point

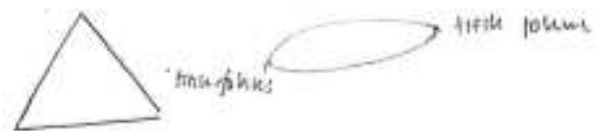

Fig. 6. The answer of each subject about Area in the Ellipse Problem

\section{E. Analysis of Problem Number 5}

The questions provided are:

A lighthouse was located at coordinates $O(0,0)$. A boat appeared in the distance, leading to the lighthouse and almost bumped into it. However, the boat successfully turned and established hyperbolic equations, $\frac{x^{2}}{900}-\frac{y^{2}}{400}=1$. If the track distance mentioned in meters, determine the shortest distance from the lighthouse boat and sketch the graph! 
Problem number 5 is the problem of the distance from the center point to the breaking point. The subject can solve it by pulling the square root of 900 . Here are the answers to each

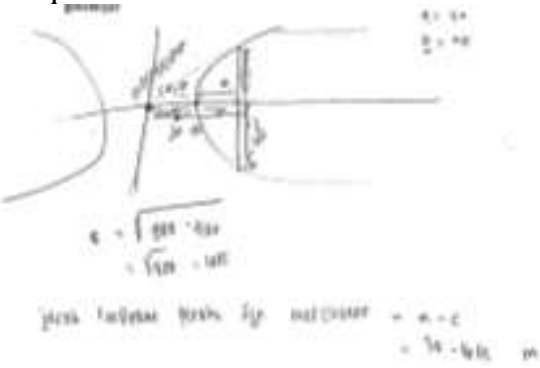

(i)

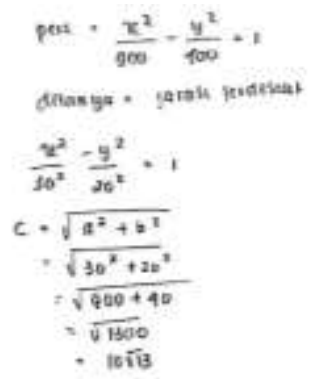

(ii) subject in solving the problem of center point of the hyperbolic

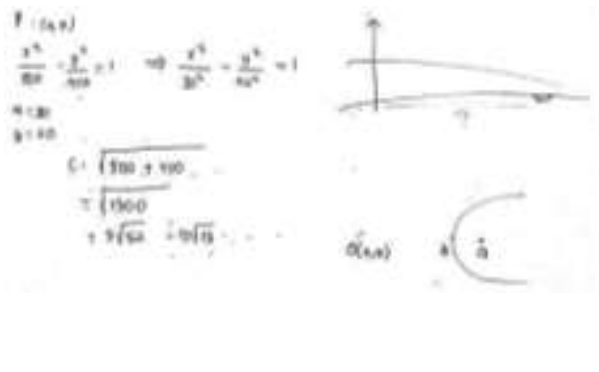

(iv)

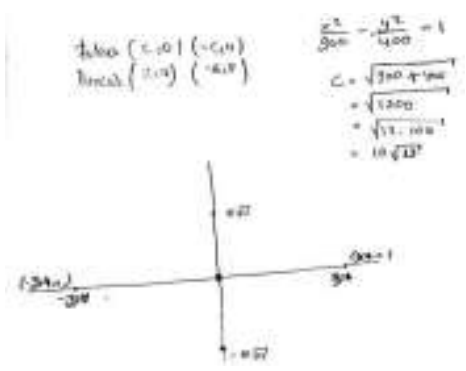

(v)

Fig. 7. The answer of each subject about Peak Point of Hyperbolic Problem

See Fig. 7(i); Subjects 1 can solve the problem about the distance of the center point to the peak point to the inventising layer. Subject 1 is less able to create the mathematical structure on the peak point distance to the center point, but the subject 1 less have an idea for using $\sqrt{a^{2}-b^{2}}$ which are supposed to be $\sqrt{a^{2}+b^{2}}$ and do not understand the position of the point $a$ and $c$. See Fig. 7(ii); Subject 2 can solve the problem about the distance of the center point to the peak point until observing layer. Subject 2 could determine the value of $c$ but was unable to continue. Subject 2 suggested that the closest distance from the lighthouse boat not be fully solved, but the subject believed that the value $c$ is not a solution. Fig. 7(iii), Subject 3 can solve problems about the distance of the center point to the peak point until primitive knowing layer. Subject 3 can only mention the equation is known and within the track questioned, however subject 3 had no idea at all about completing the work. Subject 4 can solve the problem about the distance of the center point to the peak point until inventising layer. Subject 4 cannot create the mathematical structure for assuming that the closest distance of the boat to the lighthouse is $c$ supposed to be $a$ and the answer of this problem by Subject 4 in Fig. 7(iv). In Fig. 7(v),
Subject 5 can solve problems on the distance of the center point to formalising layer. Subject 5 can connect the values of $a, b$, and $c$ for determining the value of $c$ by substituting values of $a$ and $b$. Subject 5 is less precise in placing point $c$ on the $y$-axis which is supposed to be located on the $x$-axis than the others.

\section{F. Problem Analysis Number 6}

The questions provided are:

At a carnival, a designer was going to create a funhouse. He planned to make a hyperbolic-shaped glass in the funhouse. They designed the hyperbole-shaped glass with the main symmetry axis in the $x$-axis, and the asymptotic equation $y=9 x$ and $y=-9 x$. Meanwhile, the hyperbolic peak coordinates are $(-1,0)$ and $(1,0)$. Find the equation of the hyperbolic!

Problem number 6 is the problem of hyperbolic equations. The subject can solve it by identifying the long main axis of the coordinate axes peak and its axis of the asymptotic equation then substituting it into the general equation of hyperbolic. Here are the answers to each subject in solving the equation of the hyperbolic! 


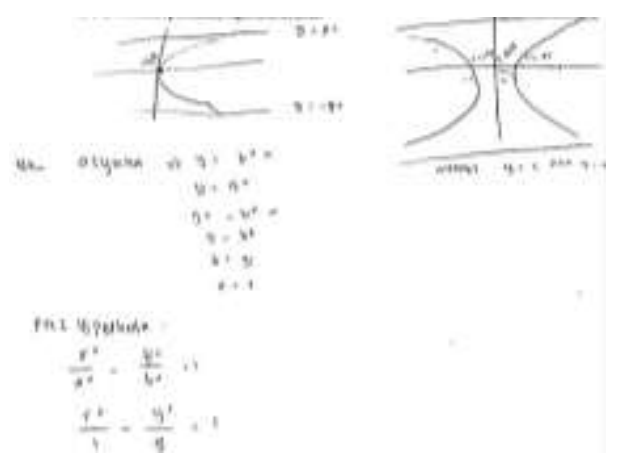

(i)

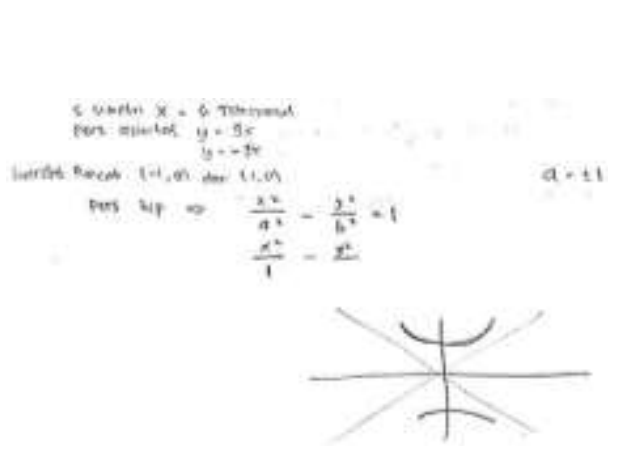

(iii)

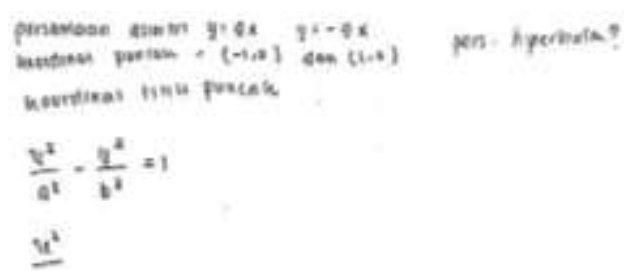

(ii)

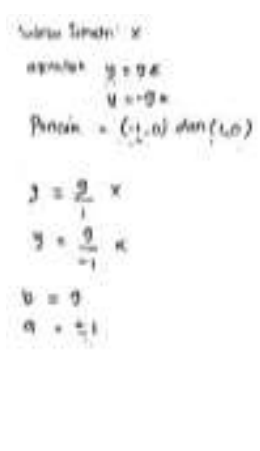

(iv)

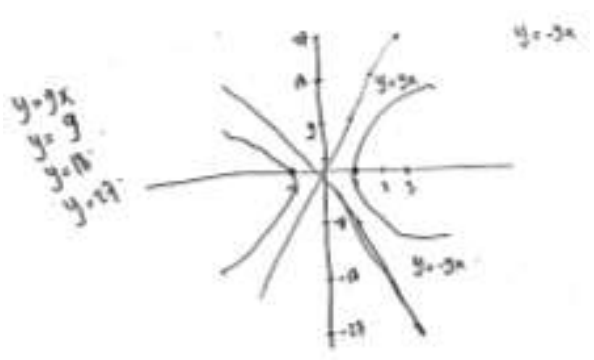

(v)

Fig. 8. The answer of each subject about Hyperbolic Equation Problem

Based on test results and interview, Subject 1 can solve problems regarding hyperbolic equations to inventising layer. Subject 1 is quite able to create the mathematical structure of the hyperbolic equation. However, Subject 1 using the general asymptote equation less precise $y=b^{2} x$ supposed to be $y= \pm \frac{b}{a} x$. Based on test results and interview, subject 2 can solve the problem regarding hyperbolic equations until the image having layer and Subject 1 answer can see in Fig. 8(i). In Fig. 8(ii), Subject 2 can solve the problem in the abstract that is to write the hyperbolic equation well, but Subject 2 does not know the next steps to solve the problem. In Fig. 8(iii), Subject 3 can solve the problem of hyperbolic equations to property noticing layer. Subject 3 cannot reconnect with the previous concept. Subject 3 is able to determine the value of $a$, but can't determine the value of $b$. In Fig. 8(iv), Subject 4 can solve problems regarding hyperbolic equations to inventising layer. Subject 4 can create a mathematical structure accurately. Subject 4 knows the asymptotic equation and hyperbolic equations are then substituted. At first, subject 4 assumes that there are two equations, as subject 4 find $a$ has two, i.e., \pm 1 , but the subject 4 soon realized that the value $1^{2}$ and $(-1)^{2}$ is the same as the 1 . In Fig. 8(v), Subject 5 can solve problems regarding hyperbolic equations until the image having the layer. Subject 5 is able to describe asymptote well through line equation. Subject 5 defines several values of $x$ and obtain values $y$ to get some coordinate points, and then the subject 5 can draw the asymptotic line and its hyperbolic.

\section{G. Problem Analysis No. 7}

The questions provided are:

An object moves along the trajectory of the hyperbolic with the equation $\frac{y^{2}}{9}-\frac{x^{2}}{36}=1$. A satellite is launched with a straight line, and the aim is to approach the moving objects without hitting it. Is there a straight line equation that meets the criteria? Mention the two equation!

Problem number 7 is the problem of the asymptotic hyperbolic. Subjects need to determine that the criteria in the 
illustration are the asymptotic line. Subjects then seek asymptotic equation by determining the major axis and the same axis of hyperbolic equations and then substituting it into the general asymptotic equation. Here are answers to each subject in solving the asymptotic equation of the hyperbolic.

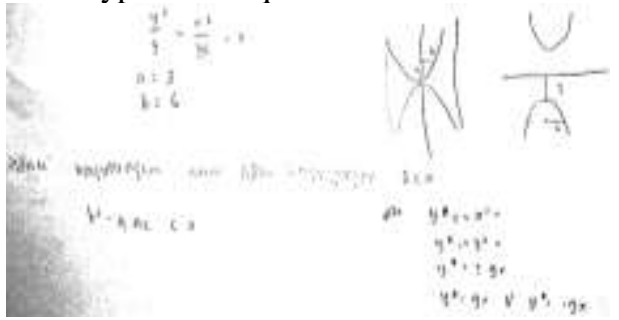

(i)

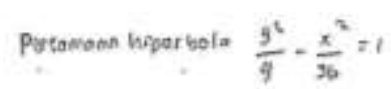

(iii)

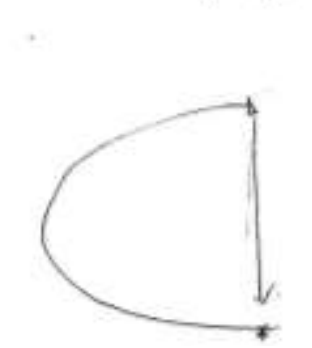

(iv)

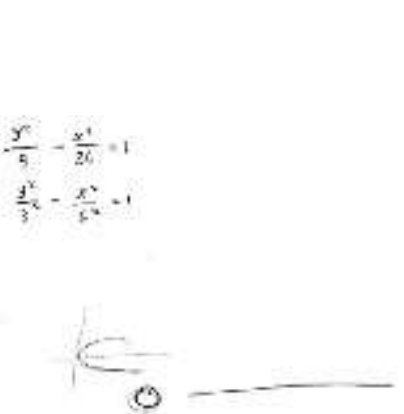

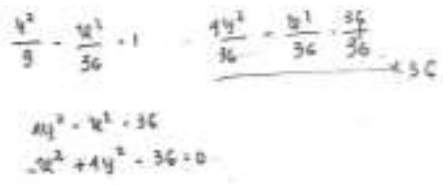

(ii)

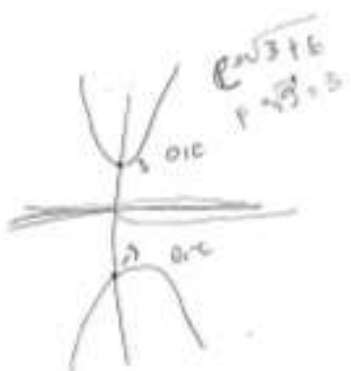

(v)

Fig. 9. The answer of each subject about Asymptotic Equation Problem

Based on test results and interview, in Fig. 9(i) we see that Subject 1 can solve problem number 7 until inventising layer. Subject 1 is able to solve well. However subject 1 using the general equation of the asymptote improperly, $y=a^{2} x$ it is supposed to be $y= \pm \frac{a}{b} x$. In Fig. 9(ii), Subject 2 can solve the problem about asymptotic hyperbolic until image making layer. Subject 2 is able to finish the picture randomly without knowing for sure the next solution. Subject 2 tried to equate the denominator of an equation. However, these steps do not help subject 2 in determining the solution. In Fig. 9(iii), Subject 3 can solve the problem about the asymptotic hyperbolic to image making the layer. Subject only draws a parabola facing to the right and a circle that represents the objects move randomly without knowing for sure what steps

\section{CONCLUSION}

Based on the results of the written test and interview analysis, Understanding Layers Mathematics Education Student of 2016 FKIP UKSW in solving Conic Section problem are:

1. On problem of determining a point on the circle, all subjects can solve up to inventising layer.

2. On parabolic equation problem, there are three subjects had solved it until inventising layer, while each subject has image making layer and image having the layer. On parabola focal point problem, there are three subjects had solved it until image making layer, while on the inventising layer and the image having layer are found one subject each.

3. On the problem about the focal point of the parabola, three subjects solved the problem in the image making to take next. In Fig. 9(iv), Subject 4 can solve the problem about the asymptotic hyperbolic to image making the layer. Subject 4 can only draw a parabola facing to the right side, and a star with an arrow pointing downward represents the objects move randomly without knowing what steps to take next. In Fig. 9(v), Subject 5 can solve the problem on the asymptotic hyperbolic until the image having the layer. Subject 5 is able to determine the breaking point in the abstract of the hyperbolic equation which is $(+3.0)$, however subject 5 assumes that the peak point is $( \pm c, 0)$, in fact, it is supposed to be $( \pm a, 0)$. level. There is one subject in both inventising and image having the level.

4. On problem of the area in Ellipse, there are three subjects had solved it up to image making layer, while the inventising layer and property noticing layer are found one subject each.

5. As the problem about the distance of the center points to the peak point, there are two subjects have solved it up to inventising layer, whereas observing layer, primitive knowing layer, and formalising layer are found one subject each.

6. On hyperbole equation problem, there is one subject that has solved it up to property noticing layer, while the inventising layer and image having layer are found two subjects each.

7. On asymptotic hyperbole problem, there are three subjects has solved it up to image making layer, while 
the inventising layer image having layer are found one subject each achievement and time of learning process in this student class is not active.

\section{REFERENCES}

[1] Afrilianto, M., Peningkatan Pemahaman Konsep dan Kompetensi Strategis Matematis Siswa SMP dengan Pendekatan Metaphorical Thinking, Jurnal Ilmiah Program Studi Matematika STKIP Siliwangi, Bandung, 2012, Vol 1, No.2, September 2012.

[2] Lampiran Peraturan Menteri Pendidikan Nasional Nomor 21 Tahun 2016 tentang Standar Isi Pendidikan Dasar dan Menengah. http://bsnpindonesia.org/wp-

content/uploads/2009/06/Permendikbud Tahun2016 Nomor021 La mpiran.pdf

[3] Utami \& Rosyidi, Profil Lapisan Pemahaman Property Noticing Siswa pada Materi Logaritma Ditinjau dari Perbedaan Jenis Kelamin, Surabaya:Jurnal Ilmiah Pendidikan Matematika, 2016, Volume 1 No. 5, ISSN : 2301-9085

[4] Syahri \& Isran, Pembelajaran Matematika dengan Model Teori Pirie dan Kieren. Edudikara, 2016, Vol. 1(1);42-50, ISSN 2541-0261

[5] Pirie, S., Kieren, T, Growth in mathematical understanding: How can we characterize it and how can we represent ii. Education Studies in Mathematics, 1994, Volume 9, pp 165-190.

[6] Sagala, Viktor, Profil Lapisan Pemahaman Konsep Turunan Fungsi dan Bentuk Folding Back Mahasiswa Calon Guru Berkemampuan Matematika Tinggi Berdasarkan Gender, Journal of Mathematics Education Science and Technology, 2016, Vol. 1, No. 2, December 2016. pp 47-62

[7] Susiswo, Folding Back Mahasiswa dalam menyelesaikan Masalah Limit, Disertasi, Universitas Negeri Malang, 2014. 